\title{
Microbial Pre-exposure and Vectorial Competence of Anopheles Mosquitoes
}

\author{
Constentin Dieme ${ }^{1,2}$, Brice Rotureau ${ }^{3}$ and Christian Mitri ${ }^{1,2 *}$ \\ ${ }^{1}$ Genetics and Genomics of Insect Vectors Unit, Department of Parasites and Insect Vectors, Institut Pasteur, Paris, France, \\ ${ }^{2}$ Centre National de la Recherche Scientifique Unit of Hosts, Vectors and Pathogens (URA3012), Paris, France, \\ ${ }^{3}$ Trypanosome Transmission Group, Trypanosome Cell Biology Unit, Institut National de la Santé et de la Recherche \\ Médicale U1201 and Department of Parasites and Insect Vectors, Institut Pasteur, Paris, France
}

OPEN ACCESS

Edited by:

Miguel Prudêncio,

Instituto de Medicina Molecular (IMM),

Portugal

Reviewed by:

Antonio M. Mendes, Instituto de Medicina Molecular (IMM),

Portugal

Julien Francis Pompon,

Duke Medical School, National University of Singapore, Singapore

*Correspondence: Christian Mitri christian.mitri@pasteur.fr

Received: 15 September 2017 Accepted: 23 November 2017 Published: 07 December 2017

Citation:

Dieme C, Rotureau B and Mitri C (2017) Microbial Pre-exposure and Vectorial Competence of Anopheles Mosquitoes.

Front. Cell. Infect. Microbiol. 7:508. doi: 10.3389/fcimb.2017.00508
Anopheles female mosquitoes can transmit Plasmodium, the malaria parasite. During their aquatic life, wild Anopheles mosquito larvae are exposed to a huge diversity of microbes present in their breeding sites. Later, adult females often take successive blood meals that might also carry different micro-organisms, including parasites, bacteria, and viruses. Therefore, prior to Plasmodium ingestion, the mosquito biology could be modulated at different life stages by a suite of microbes present in larval breeding sites, as well as in the adult environment. In this article, we highlight several naturally relevant scenarios of Anopheles microbial pre-exposure that we assume might impact mosquito vectorial competence for the malaria parasite: (i) larval microbial exposures; (ii) protist co-infections; (iii) virus co-infections; and (iv) pathogenic bacteria co-infections. In addition, significant behavioral changes in African Anopheles vectors have been associated with increasing insecticide resistance. We discuss how these ethological modifications may also increase the repertoire of microbes to which mosquitoes could be exposed, and that might also influence their vectorial competence. Studying Plasmodium-Anopheles interactions in natural microbial environments would efficiently contribute to refining the transmission risks.

Keywords: Anopheles, Plasmodium, malaria, vectorial competence, microbial pre-exposure

\section{INTRODUCTION}

Vector-borne diseases are a major cause of human mortality and morbidity in the World, among which malaria is a prominent threat. The two-thirds of the global population at risk for malaria infection are found in sub Saharan Africa, where 1.5-2.5 million deaths are reported every year (Vernick, 2004; Mitri et al., 2009; McGraw and O’Neill, 2013; Silbermayr et al., 2013; Smith et al., 2014; Blank et al., 2015). The devastating human malaria parasite, Plasmodium falciparum, is strictly transmitted by insect vectors of the genus Anopheles that are a necessary link in the chain of human-to-human malaria transmission (Vernick, 2004; Smith et al., 2014). Anopheles and Plasmodium genetics play a major role in determining mosquito vector competence (Riehle et al., 2006; Mitri et al., 2009; Harris et al., 2010). Other determinants such as the mosquito immunity, the ambient temperature, the mosquito diet and its microbial gut flora also play important roles in mosquito-parasite interactions (Molina-Cruz et al., 2012; Lefevre et al., 2013; Medeiros et al., 2014).

Permanent and temporary bodies of water that serve as larval habitat for wild mosquitoes are rich in diverse microbes. These larval site microbes could interact with the immune system of 
mosquito larvae in multiple ways and likely influence the pattern of immune activation in the future emerging adults (Dimopoulos et al., 1997; Gimonneau et al., 2012). Furthermore, adult female mosquitoes require successive blood meals for egg production and these bloodmeals may also contain not only Plasmodium parasites, but other micro-organisms (e.g., other parasites, viruses, bacteria) (Scott and Takken, 2012). Hence, prior to Plasmodium ingestion, the mosquito biology could be modulated at different life stages, from the egg to the young adult, by a wide range of microbes present in larval breeding sites, as well as in the adult ecosystem. Indeed, in areas where mammalian hosts carry diverse microbes, any adult mosquito female could theoretically be exposed to a wide range of organisms prior to, or together with, the ingestion of Plasmodium.

In the literature, effects of co-infections and exposure to multiple microbes have been intensely investigated in mammalian hosts, however, such studies remain scarce in their arthropod hosts (Dennison et al., 2014; Zélé et al., 2014a,b). Here, we first propose several relevant scenarios highlighting microbial exposure of Anopheles mosquito vectors that might impact their vectorial competence for Plasmodium. Then, considering that increasing insecticide resistance has been associated with significant changes in mosquito behavior (Gatton et al., 2013), we discuss how these ethological modifications might also impact the suite of microbes to which mosquitoes could be exposed, and that might also influence their vectorial competence. Overall, this opinion article aims at highlighting the benefit of a better understanding of the Plasmodium-Anopheles interaction systems in a more natural scheme that better consider relevant microbial ecosystems, a step that would be crucial for refining the transmission risk mapping and designing novel vector control strategies.

\section{LARVAL MICROBIAL EXPOSURE}

Mosquito oviposition and larval developmental stages are aquatic for about 10-15 days depending on the species, the temperature and the feeding resources. In nature, the breeding sites are rich in co-habiting microbes that could infect mosquito larvae and we reasoned that these dynamic and virtually limitless microbial repertoires might activate the immune system of the larvae and probably of the emerging adults too. A recent study provides evidences that Aedes larval exposure to different bacteria can drive variation in adult traits underlying vectorial competence for dengue virus (Dickson et al., 2017). In Cameroun, larval habits were dominated by Acinetobacteria (12-16\%), Firmicutes (11-24\%), and Protobacteria (54-74\%) phylum (Gimonneau et al., 2014). Interestingly exposition of Anopheles gambiae with natural midgut bacteria such as Escherichia coli, Serratia marcescens, and Pseudomonas stutzeri, which all belong to the most abundant Proteobacteria phylum, negatively impact on Plasmodium infection (Tchioffo et al., 2013).

The characterization of these microbial communities in the mosquito larval habitat remains scarce in the literature. However with the recent development of next generation sequencing (NGS) technologies, such studies will become more affordable for identifying new bacteria (Gimonneau et al., 2014), viruses, as well as protists (Belda et al., 2017) communities that might specifically shape the immune system of the mosquito larvae and probably the vectorial competence of the emerging Anopheles adults (Figures 1A,B).

\section{PROTIST CO-INFECTIONS IN ANOPHELES MOSQUITOES}

\section{Multiple Plasmodium Clones and Species}

Several studies have shown that humans co-infected with distinct clones of $P$. falciparum are common in regions of high malaria transmission (Smith et al., 1999; Joshi et al., 2007). This also means that Anopheles mosquitoes biting a human host that carries multiple clones of Plasmodium gametocytes will have to deal simultaneously with parasites of distinct genetic backgrounds. It was reported that monoclonal infections of $P$. falciparum are efficiently controlled by the mosquito immune system whereas multi-clonal infections tend to escape from the mosquito immune surveillance (Nsango et al., 2012). How distinct Plasmodium clones and/or species cohabit and/or compete with each other in different Anopheles genetic background, and what the consequences of such co-habitations are on the parasite transmission remain important questions that have been poorly addressed. One noticeable exception study has identified a new axis of mosquito resistance to monoclonal $P$. falciparum infections that includes the AP-1 transcription factor Fos and the transglutaminase 2 (TGase2) (Nsango et al., 2013).

In addition, very few studies have investigated the impact of Plasmodium-drug resistance on Anopheles vectorial competence. Artemisinin-based combination therapies are now the World Health Organization (WHO) recommended first-line treatment for $P$. falciparum malaria in all countries with endemic disease. However, there are increasing concerns about artemisininresistant strains of P. falciparum in Asia (Kone et al., 2010; Amaratunga et al., 2012; Roper et al., 2014), and more recently in Africa (Roper et al., 2014; Lu et al., 2017; Madamet et al., 2017). Furthermore, detection of Plasmodium gametocytes in artemisinin-resistant strains indicates that they can be transmitted to the mosquito vector (Tun et al., 2015). In a Plasmodium-multi-clonal scenario, Anopheles mosquitoes could ingest both sensitive and resistant clones simultaneously or successively. Therefore, it will be important to know the impact of drug-resistant parasites on transmission of drug sensitive Plasmodium by Anopheles mosquitoes.

Human malaria was known to be caused by five Plasmodium species: P. falciparum, Plasmodium vivax, Plasmodium malariae, Plasmodium ovale and since 2008, Plasmodium knowlesi has been considered as the fifth human malaria parasite (CoxSingh and Singh, 2008). A longitudinal study performed in a holoendemic area of Senegal showed that in all seasons, $A n$. gambiae s.l and Anopheles funestus are often simultaneously infected by two or three species of Plasmodium (Trape et al., 1994). Although the most deadly human malaria parasite, $P$. falciparum, is highly studied, $P$. vivax also has attracted a broad interest because it is widely distributed and causes recurring 


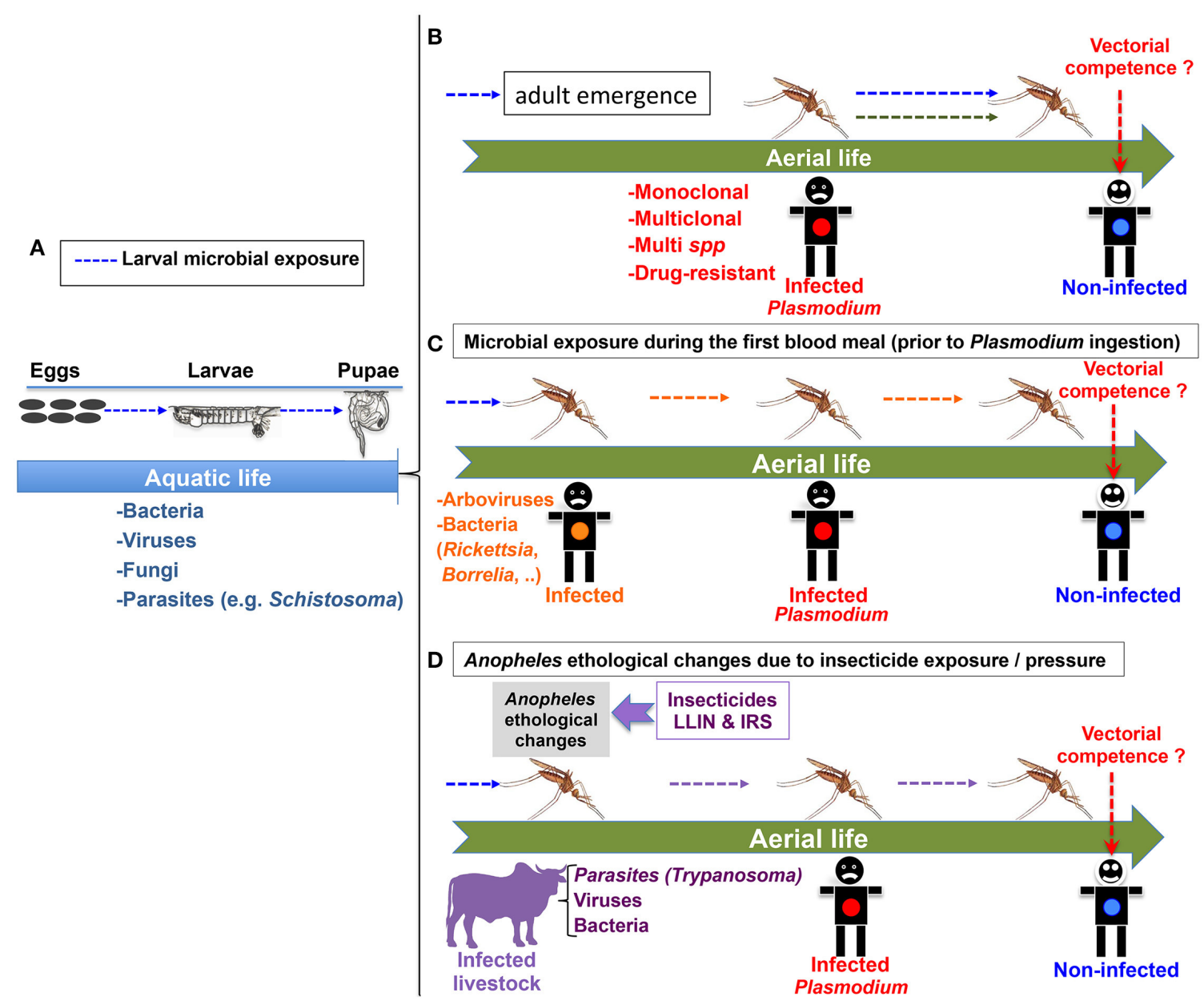

FIGURE 1 | Different scenarios for microbial pre-exposure of Anopheles mosquitoes that might impact their vectorial competence for the malaria parasite Plasmodium. (A) Larval microbial exposure (blue arrows) could impact the vectorial competence of future adult mosquito females. (B) Microbial exposure during the larval stages could impact the vectorial competence of adult mosquito females (blue arrows). The green arrow represents the possible effect of a multi-clonal or multi-species (including drug resistant strains) Plasmodium ingestion on the vectorial competence of Anopheles. (C) Microbial exposure (in orange) during the first blood meal could modulate vectorial competence. The human reservoir with an orange dot could be infected with diverse microbes. (D) One example of environmental change: Anopheles ethological changes resulting from insecticide exposure/pressure may increase the repertoire of microbial pre-exposure, as Anopheles mosquitoes could adapt their feeding preferences and feed on infected animals possibly carrying a wide range of microbes. For (B-D): The cartooned man with red dot is infected with Plasmodium gametocytes. The one with a blue dot is not infected, but could potentially become infected depending on the vectorial competence of the co-infected vector.

malaria. It was initially thought that a high proportion of African people are resistant to $P$. vivax because they lack the Duffy antigen required for $P$. vivax erythrocyte invasion. However, recent studies have indicated that Duffy-negative people were actually not fully protected against $P$. vivax (Ryan et al., 2006; Woldearegai et al., 2013; Lover, 2014; Gunalan et al., 2016). Indeed, clinical vivax malaria was identified in Duffy-negative subjects with $P$. vivax mono-infections, but also in co-infections with other Plasmodium species (Menard et al., 2010). In Kenya, An. gambiae and An. funestus were found positive for the P. vivax circumsporozoite protein, suggesting potential transmission of $P$. vivax by African malaria vectors (Ryan et al., 2006). Therefore, co-infection by multi-Plasmodium species in mosquitoes could occur more frequently than previously thought in Africa. How these distinct Plasmodium species interact within Anopheles, and what this means for vectorial competence for each parasite species is unknown (Figure 1B). To tackle this issue, one could, for instance, feed Anopheles mosquitoes on blood from patient carrying both $P$. falciparum and $P$. vivax, and further monitor the sporogonic development of each parasite species in the vector using a qPCR approach to detect species-specific gene target.

\section{Plasmodium and Trypanosoma}

Sleeping sickness (Human African Trypanosomiasis) and nagana (Animal African Trypanosomiases) are neglected tropical diseases caused by flagellated protists of the Trypanosoma genus that are transmitted by a specific blood feeding insect vectors, the tsetse fly. Nagana has devastating socio-economic 
consequences on animal production in Africa (Rotureau and Van Den Abbeele, 2013). African trypanosomes circulate in 37 subSaharan countries where approximately 70 million people and about 50 million cattle are currently living at risk of infection. Less than 3,000 new human cases were reported to WHO in 2015, 98\% of which being caused by Trypanosoma brucei gambiense (Buscher et al., 2017). In many areas, tsetse flies and mosquitoes currently share the same habitat, and both human and animal African trypanosomiases occur in areas where malaria is also endemic. Blum et al. reported a malaria prevalence of $50 \%$ in T.b. gambiense patients from several endemic countries (Blum et al., 2006). In Alupe Kenya, between 2000 and 2009 amongst 31 HAT cases recorded from the National Sleeping Sickness Referral Hospital, 100\% were found co-infected with malaria parasites (Kagira et al., 2011). Given that trophic behavioral changes have been recently discovered in Anopheles mosquitoes initially described as exclusively anthropophilic (see section below), the occurrence of successive infections by Trypanosoma and Plasmodium in Anopheles mosquitoes may increase to measureable frequencies. It is therefore important to carry out studies to determine the impact of such co-infections on the natural cyclical development of Plasmodium in Anopheles mosquitoes, and consequently on its transmission (Figure 1D).

\section{Plasmodium and Helminths}

Schistosomiasis kills 20,000 to 200,000 people every year $\left(\mathrm{WHO} \text { Fact_Sheet_N } \mathrm{N}^{\circ} 115,2016\right)^{1}$ The disease is most commonly found in Africa, as well as in Asia and South America, and is due to a human parasite called Schistosoma $\left(\text { WHO_Fact_Sheet_N }{ }^{\circ} 115,2016\right)^{1}$. Schistosoma larvae develop in an aquatic environment. Parasite eggs are laid in water within human feces or urine. After hatching, eggs release miracidia $(\sim 150 \mu \mathrm{m})$, the free-swimming larval stages that infect a specific snail (the intermediate host), in which the parasites develop into sporocysts and finally into cercariae. Swimming cercariae released from snails are the only infective forms for humans. Malaria and schistosomiasis are co-endemic in many areas of Africa, and co-infections can occur in humans (Brooker et al., 2007; Naing et al., 2013). A study performed in Ethiopia showed that among malaria febrile patients, $38 \%$ were co-infected with S. mansoni (Degarege et al., 2012). Moreover, coinfections with Plasmodium and Schistosoma infection have known implications for the health of children of all ages in sub-Saharan Africa (Sokhna et al., 2004; Wilson and Dunne, 2012). It is noteworthy that the aquatic environment is a common phase for the development of both schistosome and mosquito larvae. Although it is poorly documented, Schistosoma host snails and mosquito larvae are commonly found in the same larval sites (Ofulla et al., 2010). Therefore, assuming that mosquito larvae are exposed to Schistosoma miracidia in co-endemic areas, it could be interesting to assess how this exposure could affect the mosquito biology, especially their survival at the larval stages (i.e., the rate of successful adult emergence) as well as their susceptibility to Plasmodium in adult mosquitoes previously exposed to miracidia during their larval stage (Figure 1A). The

${ }_{1}^{1}$ http://www.who.int/mediacentre/factsheets/fs115/en/ miracidia $(150 \mu \mathrm{m})$ could be ingested by Anopheles larvae or attached to the larval cuticle. In the latter case, we could not exclude the possibility for the miracidia to penetrate the cuticle of mosquito larvae: using a genetically modified parasite expressing a fluorescent protein could help assessing this issue. For the ingestion scenario, it is known that excretory-secretory products released during transformation of miracidia to sporocyst in the invertebrate host snail, can impair phagocytosis and reduce the production of reactive oxygen species from snail's haemocytes (Connors and Yoshino, 1990). Therefore assuming that miracidia could reach the larvae midgut, excretory-secretory (ES) products might also affect the mosquito physiology e.g., by modifying the midgut environment and/or the larval bacteria flora. Other possible effects of these ES products, as described in the host snail (Lockyer et al., 2012; Pinaud et al., 2016), could be long-term modifications of the larvae immune system that might also affect the vector competence of the emerging adult.

Others helminthiasis, such as lymphatic filariasis (LF) and onchocerciasis due to Wuchereria bancrofti and Onchocerca volvulus respectively are also co-endemic with malaria (Brooker et al., 2007; Muturi et al., 2008). Although O. volvulus is transmitted to the human host by the black fly and potentially by Aedes (Zielke et al., 1977), Anopheles mosquito are known to be competent vector for the parasite responsible for LF (Boakye et al., 2004; Muturi et al., 2008). Therefore, W. bancrofti could theoretically be in contact with Plasmodium parasites ingested with another blood meal. In this particular case, future studies could tackle how the successive or concomitant presence of the two parasites (Wuchereria and Plasmodium) could affect their respective transmission by Anopheles mosquito vectors.

\section{PLASMODIUM AND VIRUSES CO-INFECTIONS IN ANOPHELES MOSQUITOES}

\section{Plasmodium and Arboviruses}

Although arboviruses, such as dengue, chikungunya, or yellow fever viruses, and Plasmodium infections differ in their development cycles and transmission dynamics, some similar ecological traits suggest that interactions between these microorganisms could occur within their hosts. Several reports described arbovirus and Plasmodium co-infections in humans throughout the World (Epelboin et al., 2012; Medeiros et al., 2014), e.g., malaria and dengue mixed infections are common in the field (Carme et al., 2009). Their co-circulation within a given human host population increases the probability of concurrent mosquito vector infections (Medeiros et al., 2014). Mosquitoes can become co-infected when they bite a human host harboring both malaria parasites and arboviruses. Another scenario by which mosquitoes may become infected by both Plasmodium spp. and arboviruses is consecutive bites on two different singly infected hosts. In addition, field caught malaria vectors such as An. funestus and Anopheles coustani have been found to carry arboviruses such as Chikungunya, Zika, and yellow fever viruses, emphasizing the plausibility of Anopheles exposition to arboviruses (Sow et al., 2016). Anopheles coluzzi is 
also the vector of the O'nyong nyong arbovirus, against which it develops an immune response that is accompanied by peculiar modifications and activities of the bacterial gut flora (Carissimo et al., 2015). While Anopheles mosquitoes are not important vectors for the majority of arboviruses, the sole fact of being exposed to these viruses, even for periods as short as $12-24 \mathrm{~h}$, could significantly impact on their biology, especially in the midgut. For instance, Dengue virus serotype-2 (DENV-2) can be detected in An. coluzzi until $24 \mathrm{~h}$ post ingestion (Unpublished result). Anopheles midgut is known to be the first organ where Plasmodium starts its sporogonic development, and is also the first bottleneck for the parasite population in the mosquito (Han et al., 2000). Any arbovirus could potentially immune-prime Anopheles mosquito and further impact on the invasion and development of Plasmodium (Medeiros et al., 2014) (Figure 1C). For example, one could perform a first infectious feeding of Anopheles females with DENV, followed with a second infectious blood meal containing Plasmodium parasites 3-4 days later. In the control group, the first blood meal should be non-infected. This experiment would allow assessing whether DENV preexposure could impact the vectorial competence of Anopheles for Plasmodium.

\section{Plasmodium and HIV}

The human immunodeficiency virus (HIV) is a lentivirus that causes HIV infection and over time acquired immunodeficiency syndrome (AIDS) (Weiss, 1993). HIV continues to be a major global public health issue, having claimed more than 35 million lives so far. In 2016, 1.0 million people died from HIVrelated causes globally (WHO_Fact_Sheet_HIV/AIDS, 2017) ${ }^{2}$ The African region, which is the most affected with 25.6 million people living with HIV, accounts for almost two thirds of the new HIV infections (WHO_Fact_Sheet_HIV/AIDS, 2017) ${ }^{2} \mathrm{HIV}$ 1 and $P$. falciparum malaria therefore remain two of the major causes of morbidity and mortality in Sub-Saharan Africa where they are sympatric (Andreani et al., 2012; Orlov et al., 2012). In a population of about 200,000 people that have been exposed to both pathogens since 1980 in Kenya, the interaction of the two diseases may have caused 8,500 excess HIV infections and 980,000 excess malaria episodes (Abu-Raddad et al., 2006). Many studies have focused on the impact of the simultaneous presence of these two pathogens (HIV and Plasmodium) on their respective development in humans, and on the severity of the diseases (AIDS and malaria), however the effect of the presence of both pathogens in Anopheles mosquitoes is not known. While the HIV virus is not transmitted by mosquitoes, it is noteworthy that it has a short lifespan in their digestive tract (48 h) (Bockarie and Paru, 1996; Iqbal, 1999). Therefore, during this time frame $(48 \mathrm{~h})$, proteins from the virion surface could induce an immune response in Anopheles mosquitoes biting on a co-infected human host, which may further impact on the development of Plasmodium. Chemical inactivation of the HIV-1 virus has been shown to be immunogenic (Rossio et al., 1998), suggesting that the conformation of the surface proteins from inactivated virions is still intact. To further assess the potential

${ }^{2} \mathrm{http} / / / \mathrm{www}$. who.int/mediacentre/factsheets/fs360/en/ impact of HIV surface proteins on the sporogonic development of Plasmodium in Anopheles, chemically inactivated HIV-1 could be mixed with Plasmodium gametocytes to co-infect Anopheles mosquitoes.

\section{MALARIA AND BACTERIA CO-INFECTIONS IN MOSQUITOES}

The mosquito midgut can possibly contain some pathogens harmful to humans, but also a complex ecosystem composed by diverse bacterial communities that may vary depending on the geographical origin, the ecological niche, the season and the source of food (Dennison et al., 2014; Tchioffo et al., 2015). Mosquitoes are continuously exposed to a variety of microbes originating from both their aquatic and aerial ecosystems; some of these microbes develop a symbiotic relationship with the insect, while others are commensal or pathogenic (Dennison et al., 2014).

\section{Domesticated Bacteria Gut}

There is strong evidence that bacteria influence mosquito susceptibility to human pathogens as well as their capacity to transmit them (Dong et al., 2009; Boissiere et al., 2012; Saraiva et al., 2016). Recent studies have suggested that microbiota might influence Plasmodium development directly through the production of antimalarial compounds, or more indirectly by maintaining basal immune activity, or through resources competition (Dennison et al., 2014; Smith et al., 2014; Saraiva et al., 2016). Interestingly, co-feeding of an Enterobacter bacterium isolated from wild mosquito populations in Zambia, with Plasmodium gametocytes, renders Anopheles mosquitoes resistant to human malaria P. falciparum parasites through the production of reactive oxygen species (Cirimotich et al., 2011).

Wolbachia, is a Gram-negative endosymbiont commonly found in Arthropods (in 60\% of insects). Although present in several mosquito species, including Culex pipiens and Aedes Albopictus, Wolbachia is not naturally present in any anopheline species that transmitsmalaria parasites, nor in Ae. aegypti (vector of the dengue virus). Wolbachia from Drosophila fruit flies, strain wMelPop, or from the mosquito Ae. Albopictus, strain $w$ Alb, have experimentally been introduced in Ae. aegypti and Anopheles species. Each of these Wolbachia strains, introduced in Ae. aegypti, reduces the ability of certain viruses, such as dengue and chikungunya viruses, to develop in these mosquitoes (Moreira et al., 2009; Walker et al., 2011; Mousson et al., 2012). However, the effects of Wolbachia on Plasmodium development in the mosquito are not fully understood (Hughes et al., 2014). Introduction of both Wolbachia strains wMelPop and wAlb in An. stephensi mosquitoes induced their refractoriness to the human malaria parasite P. falciparum (Bian et al., 2013). However, the opposite effect is observed when An. gambiae mosquitoes carrying the $w$ AlB strain are infected with the rodent malaria parasite Plasmodium berghei (Hughes et al., 2012). Similarly, another study showed that the Wolbachia $w P i p(S l)$ strain increases the susceptibility of C. pipiens 
mosquitoes to the avian parasite Plasmodium relictum (Zélé et al., 2014a), suggesting that Wolbachia-infected mosquitoes may also have an opposite effect to that observed on the vectorial competence of Aedes and Anopheles for dengue and $P$. falciparum, respectively. The reasons for such contrasting results remain unknown. One potential explanation is the disparity of the immune modulation mediated by different strains of Wolbacchia that could, in turn, differentially impact the pathogenic microbes transmitted by different species of mosquito vectors. Another reason could be the impact of Wolbachia on the midgut environment, and probably on the entire composition of the microbiota in the mosquito midgut (McGraw and O’Neill, 2013; Smith et al., 2014; Zélé et al., 2014a,b). A recent study indicated that Wolbachiaaltered cholesterol is responsible for the viral refractoriness in Aedes cells (Geoghegan et al., 2017). The Plasmodium parasite is unable to synthesize cholesterol de novo, as it can access cholesterol from the host via either the endogenous or exogenous pathways (Labaied et al., 2011). Therefore, we cannot exclude that, like in Aedes cells, Wolbachia may alter the lipid metabolism of Anopheles mosquitoes, which in turn may inhibit the sporogonic development of Plasmodium in the mosquito host. Moreover, a novel Wolbachia strain, distinct from strains infecting other arthropods, has been identified in Anopheles gambiae from Burkina Faso, West Africa (Baldini et al., 2014). This emphasizes the need for further investigations on the possible use of natural Wolbachia-Anopheles associations to limit malaria transmission.

In Cairns, Australia, Wolbachia has been successfully spread through mosquito populations, in order to reduce the transmission of dengue and zika viruses (Jiggins, 2017). However, due to the inconsistent effects of Wolbachia on the transmission of distinct pathogens, such strategies for controlling vector competence should be cautiously implemented and monitored in the field (Figure 1C).

\section{Pathogenic Bacteria}

A large panel of tick-borne diseases, which affect both humans and wild mammals, can result from the transmission of several pathogens including bacteria, viruses, and protists. It is known that ticks can harbor and co-transmit multiple pathogens (Knapp and Rice, 2015). Malaria and tick-borne diseases overlap in many African regions, therefore co-infections in Anopheles mosquitoes may be possible after successive or concomitant infectious blood meals on hosts carrying both micro-organisms. In African malaria-endemic regions, bacteria such as Rickettsia, Borrelia, Bartonella, and Coxiella are often the cause of misdiagnosed malaria-like fever cases (Mediannikov et al., 2013; Fotso Fotso and Drancourt, 2015; Mourembou et al., 2015; Angelakis et al., 2016; Cutler et al., 2016; Sothmann et al., 2017). In Sub-Saharan Africa, Borreliainduced mortality rate is estimated at between 2 and $5 \%$ (Fotso Fotso and Drancourt, 2015), and in rural Senegal, the incidence of tick-borne relapsing fever is estimated to reach 11\% (Fotso Fotso and Drancourt, 2015; Cutler et al., 2016). Rickettsioses are a major public health problem in sub-Saharan Africa (Mediannikov et al., 2013; Mourembou et al., 2015;
Sothmann et al., 2017). Rickettsia felis and Plasmodium coinfections were found in humans (Mediannikov et al., 2013) and recent studies showed that mosquitoes can readily transmit pathogenic bacteria such as $R$. felis and Francisella tularensis (Backman et al., 2015; Dieme et al., 2015). Therefore, Anopheles mosquito co-infections with $P$. falciparum and Rickettsia, Borrelia, Bartonella, and/or Coxiella may occur in significant proportions in sub-Saharan Africa. How this pre-exposure or co-infection status affects the vectorial competence of Anopheles for Plasmodium is not known and certainly requires future work (Figures 1A,C). Bacteria such as Rickettsia and Borrelia can easily be cultivated and quantified (Bonnet et al., 2015; Dieme et al., 2015), and could therefore be mixed within blood for performing an experimental infection of Anopheles female. These females would then take a Plasmodium-infected blood meal to evaluate the impact of bacterial pre-exposure on their vectorial competence for Plasmodium as compared to nonexposed females.

\section{ENVIRONMENTAL CHANGES AND ANOPHELES MICROBIAL EXPOSURE}

\section{Effects of Insecticide Exposures on Anopheles Trophic Behavior}

Since 2000, prevention of malaria in Africa is largely based on vector control and especially on the individual use of insecticides in the domestic environment with either long-lasting insecticidetreated bednets (LLINs) or indoor residual spraying (IRS) (Bhatt et al., 2015; Hemingway et al., 2016; Ranson and Lissenden, 2016). These measures have significantly reduced the mortality and morbidity of malaria in Africa by $40 \%$ in 15 years (Bhatt et al., 2015). However, resistance against pyrethroids (the only chemical class used for LLINs) are widely documented in An. gambiae and An. funestus in sub-Saharan Africa (Kawada et al., 2011; Silva et al., 2014). In addition, increased resistance to pyrethroids, carbamates, and organophosphates that are routinely used in IRS programs are also observed (Aizoun et al., 2013; Riveron et al., 2016; Ondeto et al., 2017). This decrease in insecticide efficiency led to an increase of the vector population size (Bhatt et al., 2015; Hemingway et al., 2016; Ranson and Lissenden, 2016) and some studies have reported the presence of sporozoites in mosquitoes containing insecticides resistant alleles, which may significantly compromises the elimination of malaria (Alout et al., 2013; Kabula et al., 2016).

With the increasing indoor use of both LLIN and IRS, Anopheles mosquitoes tend to adapt by finding other sources of blood, especially outside housings. There are strong evidence that Anopheles behavior is shifting from indoor to outdoor biting, or from night to dawn biting in areas where LLINs are used (Russell et al., 2011; McGraw and O’Neill, 2013; Ranson and Lissenden, 2016). This strongly suggests that insecticide exposure has probably influenced mosquito behavior and fitness. An. gambiae, which is the World most important vector for Plasmodium parasites, was initially described to show a high degree of anthropophily, coupled with strong endophilic and endophagic traits (Scott and Takken, 2012; Takken and Verhulst, 
2013). However, recent studies on its feeding behavior have shown high proportions (i) of blood meals actually taken on a single non-human host (animal) and (ii) of mixed blood meals taken from both animals and humans (Diatta et al., 1998; Ngom et al., 2013). These behavioral changes may enlarge the diversity of the microbial repertoire to which Anopheles mosquitoes are exposed, and concomitantly increase the probability of co-infections with Plasmodium. Therefore, we suggest that the increasing risk of microbial pre-exposure related to these ethological changes might also impact on the vectorial competence of Anopheles for the malaria parasite (Figure 1D).

\section{Effect of Climate Changes on Anopheles Biology}

Several studies have been conducted to evaluate the impact of temperature variation and climate change on the vectorial competence of Anopheles for Plasmodium (Paaijmans et al., 2010; Gething et al., 2011; Caminade et al., 2014; Murdock et al., 2016). A recent study has investigated how temperature could affect several mosquito-parasite traits such as mortality rate, parasite extrinsic incubation period, and biting rate (Shapiro et al., 2017). While all these studies raise important issues related to the effect of temperature on Anopheles vectorial competence, the impact on Anopheles microbial exposure was not assessed.

Nevertheless, the biting rate evaluated in (Shapiro et al., 2017) could be extrapolated to microbial exposures, assuming that each biting event exposes the mosquito to microbes. In that sense, we could therefore consider that temperature variation may indirectly affect Anopheles microbial exposure. In addition, the temperature of a mosquito body is very closed to ambient temperature, hence it would also be interesting to assess whether external temperature variation might affect the composition of the bacterial gut flora, which is known to influence Anopheles vectorial competence. Similarly, larval ecological niches subjected to temperature variation might also be impacted for their microbial compositions. This could modulate the immune system of the larvae and possibly influence the pattern of immune activation in the emerging adults, and overall their vectorial competence. Further studies are needed to tackle all these different issues.

\section{Effect of Mosquito Diet}

Sources of sugar for mosquitoes include floral nectar, extrafloral nectaries, and plant fluids (Impoinvil et al., 2004; Muller et al., 2010; Gouagna et al., 2014; Faiman et al., 2017). Dietaryrestricted organisms across many taxa have been reported to survive longer than those with unlimited or normal access to food (Vellai et al., 2003; Hatle et al., 2006; Bjedov et al., 2010). A recent study has investigated the effect of dietary restriction on A. coluzzi lifespan and showed that sugar restriction significantly enhances longevity of the mosquitoes (Faiman et al., 2017). Extension of female longevity might also increase the number of blood feeding and therefore the probability of microbial exposure events.

Furthermore, several drugs such as antibiotics (Gendrin et al., 2015) or Ivermectine (Kobylinski et al., 2012), present in ingested mammal blood, were shown to affect Anopheles vector competence for Plasmodium. Therefore it would also be interesting to consider these aspects for studying the AnophelesPlasmodium system in its natural environment.

\section{CONCLUSION}

Anopheles mosquitoes are continuously exposed to a wide range of microbes from the larval aquatic stages to the aerial adult stage. In the latest stage, the obligate hematophagy of the female mosquitoes that need to take successive blood meal on multiple hosts enlarge the repertoire of microbes to which they are exposed, including Plasmodium, the deadliest parasite in the World. Many studies focusing on the AnophelesPlasmodium interaction have highlighted several mosquito factors controlling the susceptibility of the Anopheles mosquito female to Plasmodium. However, these studies have been more often performed in controlled biological systems that considered the mosquito as infected only with the Plasmodium parasite. Microbial exposure of Anopheles mosquito, prior to, or concomitant with Plasmodium ingestion, could significantly modify the vectorial competence of Anopheles for Plasmodium in distinct ways, e.g., via resource competition, modification of the midgut environment and of the bacterial gut flora, immune priming, releasing factors that might interfere directly or indirectly with the Plasmodium parasites. Figure 1 summarizes several relevant scenarios of microbial pre-exposure that could significantly impact anopheline biology, and consequently modulate their vectorial competence for Plasmodium. We assume that studying the Anopheles-Plasmodium system in its natural and dynamic environment, including relevant microbial pre-exposures, would refine our understanding of the complex mechanisms ruling the vector competence. This would be more relevant and certainly helpful for elaborating optimal antivectorial strategies.

\section{AUTHOR CONTRIBUTIONS}

$\mathrm{CD}, \mathrm{BR}$, and $\mathrm{CM}$ designed the plan, wrote, and discussed the manuscript.

\section{FUNDING}

We acknowledge the support from the Institut Pasteur "Projet Transversaux de Recherche" grant (PTR_542).

\section{ACKNOWLEDGMENTS}

We thank Michelle M. Riehle and Kenneth D. Vernick for their valuable comments and suggestions on the manuscript. 


\section{REFERENCES}

Abu-Raddad, L. J., Patnaik, P., and Kublin, J. G. (2006). Dual infection with HIV and malaria fuels the spread of both diseases in sub-Saharan Africa. Science 314, 1603-1606. doi: 10.1126/science.1132338

Aizoun, N., Aikpon, R., Gnanguenon, V., Oussou, O., Agossa, F., Padonou, G., et al. (2013). Status of organophosphate and carbamate resistance in Anopheles gambiae sensu lato from the south and north Benin, West Africa. Parasit. Vectors 6:274. doi: 10.1186/1756-3305-6-274

Alout, H., Ndam, N. T., Sandeu, M. M., Djegbe, I., Chandre, F., Dabire, R. K., et al. (2013). Insecticide resistance alleles affect vector competence of Anopheles gambiae s.s. for Plasmodium falciparum field isolates. PLoS ONE 8:e63849. doi: 10.1371/journal.pone.0063849

Amaratunga, C. S. S., Suon, S., Phelps, E. S., Stepniewska, K., Lim, P., Zhou, C., et al. (2012). Artemisinin-resistant Plasmodium falciparum in Pursat province, western Cambodia: a parasite clearance rate study. Lancet Infect. Dis. 12, 851-858. doi: 10.1016/S1473-3099(12)70181-0.

Andreani, G., Lodge, R., Richard, D., and Tremblay, M. J. (2012). Mechanisms of interaction between protozoan parasites and HIV. Curr. Opin. HIV AIDS 7, 276-282. doi: 10.1097/COH.0b013e32835211e9

Angelakis, E., Mediannikov, O., Parola, P., and Raoult, D. (2016). Rickettsia felis: the complex journey of an emergent human pathogen. Trends Parasitol. 32, 554-564. doi: 10.1016/j.pt.2016.04.009

Backman, S., Naslund, J., Forsman, M., and Thelaus, J. (2015). Transmission of tularemia from a water source by transstadial maintenance in a mosquito vector. Sci. Rep. 5:7793. doi: 10.1038/srep07793

Baldini, F., Segata, N., Pompon, J., Marcenac, P., Shaw, W. R., Dabire, R. K., et al. (2014). Evidence of natural Wolbachia infections in field populations of Anopheles gambiae. Nat. Commun. 5, 3985. doi: 10.1038/ncomms4985

Belda, E., Coulibaly, B., Fofana, A., Beavogui, A. H., Traore, S. F., Gohl, D. M., et al. (2017). Preferential suppression of Anopheles gambiae host sequences allows detection of the mosquito eukaryotic microbiome. Sci. Rep. 7, 3241. doi: $10.1038 / \mathrm{s} 41598-017-03487-1$

Bhatt, S., Weiss, D. J., Cameron, E., Bisanzio, D., Mappin, B., Dalrymple, U., et al. (2015). The effect of malaria control on Plasmodium falciparum in Africa between 2000 and 2015. Nature 526, 207-211. doi: 10.1038/nature15535

Bian, G., Joshi, D., Dong, Y., Lu, P., Zhou, G., Pan, X., et al. (2013). Wolbachia invades Anopheles stephensi populations and induces refractoriness to Plasmodium infection. Science 340, 748-751. doi: 10.1126/science.1236192

Bjedov, I., Toivonen, J. M., Kerr, F., Slack, C., Jacobson, J., Foley, A., et al. (2010). Mechanisms of life span extension by rapamycin in the fruit fly Drosophila melanogaster. Cell Metab. 11, 35-46. doi: 10.1016/j.cmet.2009.11.010

Blank, J., Behrends, J., Jacobs, T., and Schneider, B. E. (2015). Mycobacterium tuberculosis coinfection has no impact on Plasmodium berghei ANKA-induced experimental cerebral malaria in C57BL/6 Mice. Infect. Immun. 84, 502-510. doi: 10.1128/IAI.01290-15

Blum, J., Schmid, C., and Burri, C. (2006). Clinical aspects of 2541 patients with second stage human African trypanosomiasis. Acta Trop. 97, 55-64. doi: 10.1016/j.actatropica.2005.08.001

Boakye, D. A., Wilson, M. D., Appawu, M. A., and Gyapong, J. (2004). Vector competence, for Wuchereria bancrofti, of the Anopheles populations in the Bongo district of Ghana. Ann. Trop. Med. Parasitol. 98, 501-508. doi: 10.1179/000349804225003514

Bockarie, M. J., and Paru, R. (1996). Can mosquitoes transmit AIDS? P. N. G. Med. J. 39, 205-207.

Boissiere, A., Tchioffo, M. T., Bachar, D., Abate, L., Marie, A., Nsango, S. E., et al. (2012). Midgut microbiota of the malaria mosquito vector Anopheles gambiae and interactions with Plasmodium falciparum infection. PLoS Pathog. 8:e1002742. doi: 10.1371/journal.ppat.1002742

Bonnet, S., Choumet, V., Masseglia, S., Cote, M., Ferquel, E., Lilin, T., et al. (2015). Infection of Siberian chipmunks (Tamias sibiricus barberi) with Borrelia sp. reveals a low reservoir competence under experimental conditions. Ticks Tick Borne Dis. 6, 393-400. doi: 10.1016/j.ttbdis.2015.03.008

Brooker, S., Akhwale, W., Pullan, R., Estambale, B., Clarke, S. E., Snow, R. W., et al. (2007). Epidemiology of plasmodium-helminth co-infection in Africa: populations at risk, potential impact on anemia, and prospects for combining control. Am. J. Trop. Med. Hyg. 77, 88-98. doi: 10.4269/ajtmh.2007.77.88
Buscher, P., Cecchi, G., Jamonneau, V., and Priotto, G. (2017). Human African trypanosomiasis. Lancet 390, 2397-2409. doi: 10.1016/S0140-6736(17)31510-6

Caminade, C., Kovats, S., Rocklov, J., Tompkins, A. M., Morse, A. P., Colon-Gonzalez, F. J., et al. (2014). Impact of climate change on global malaria distribution. Proc. Natl. Acad. Sci. U.S.A. 111, 3286-3291. doi: 10.1073/pnas.1302089111

Carissimo, G., P. E., McFarlane, M., Dietrich, I., Mitri, C., Bischoff, E., Failloux, A. B., et al. (2015). Antiviral immunity of Anopheles gambiae is highly compartmentalized, with distinct roles for RNA interference and gut microbiota. Proc. Natl. Acad. Sci. U.S.A. 112, E176-E185. doi: 10.1073/pnas. 1412984112

Carme, B., Matheus, S., Donutil, G., Raulin, O., Nacher, M., and Morvan, J. (2009). Concurrent dengue and malaria in Cayenne Hospital, French Guiana. Emerging Infect. Dis. 15, 668-671. doi: 10.3201/eid1504.080891

Cirimotich, C. M., Dong, Y., Clayton, A. M., Sandiford, S. L., Souza-Neto, J. A., Mulenga, M., et al. (2011). Natural microbe-mediated refractoriness to Plasmodium infection in Anopheles gambiae. Science 332, 855-858. doi: $10.1126 /$ science. 120161

Connors, V. A., and Yoshino, T. P. (1990). In vitro effect of larval Schistosoma mansoni excretory-secretory products on phagocytosis-stimulated superoxide production in hemocytes from Biomphalaria glabrata. J. Parasitol. 76, 895-902. doi: $10.2307 / 3282811$

Cox-Singh, J., and Singh, B. (2008). Knowlesi malaria: newly emergent and of public health importance? Trends Parasitol. 24, 406-410. doi: 10.1016/j.pt.2008.06.001.

Cutler, S. J., Ruzic-Sabljic, E., and Potkonjak, A. (2016). Emerging borreliae - expanding beyond Lyme borreliosis. Mol. Cell. Probes 31, 22-27. doi: 10.1016/j.mcp.2016.08.003

Degarege, A., Legesse, M., Medhin, G., Animut, A., and Erko, B. (2012). Malaria and related outcomes in patients with intestinal helminths: a cross-sectional study. BMC Infect. Dis. 12:291. doi: 10.1186/1471-2334-12-291

Dennison, N. J., Jupatanakul, N., and Dimopoulos, G. (2014). The mosquito microbiota influences vector competence for human pathogens. Curr. Opin. Insect Sci. 3, 6-13. doi: 10.1016/j.cois.2014.07.004

Diatta, M., Spiegel, A., Lochouarn, L., and Fontenille, D. (1998). Similar feeding preferences of Anopheles gambiae and A. arabiensis in Senegal. Trans. R. Soc. Trop. Med. Hyg. 92, 270-272. doi: 10.1016/S0035-9203(98)91005-7

Dickson, L. B., Jiolle, D., Minard, G., Moltini-Conclois, I., Volant, S., Ghozlane, A., et al. (2017). Carryover effects of larval exposure to different environmental bacteria drive adult trait variation in a mosquito vector. Sci. Adv. 3:e1700585. doi: 10.1126/sciadv.1700585

Dieme, C., B. Y., Socolovschi, C., Audoly, G., Berenger, J. M., Faye, O., Raoult, D., et al. (2015). Transmission potential of Rickettsia felis infection by Anopheles gambiae mosquitoes. Proc. Natl. Acad. Sci. U.S.A. 112, 8088-8093. doi: $10.1073 /$ pnas. 1413835112

Dimopoulos, G., Richman, A., Muller, H. M., and Kafatos, F. C. (1997). Molecular immune responses of the mosquito Anopheles gambiae to bacteria and malaria parasites. Proc. Natl. Acad. Sci. U.S.A. 94, 11508-11513. doi: 10.1073 /pnas. 94.21 .11508

Dong, Y., Manfredini, F., and Dimopoulos, G. (2009). Implication of the mosquito midgut microbiota in the defense against malaria parasites. PLoS Pathog. 5:e1000423. doi: 10.1371/journal.ppat.1000423

Epelboin, L., H. M., Dussart, P., Ouar-Epelboin, S., Djossou, F., Nacher, M., and Carme, B. (2012). Is dengue and malaria co-infection more severe than single infections?A retrospective matched-pair study in French Guiana. Malar. J. 11, 142. doi: 10.1186/1475-2875-11-14

Faiman, R., Solon-Biet, S., Sullivan, M., Huestis, D. L., and Lehmann, T. (2017). The contribution of dietary restriction to extended longevity in the malaria vector Anopheles coluzzii. Parasit. Vectors 10:156. doi: 10.1186/s13071-017-2088-6

Fotso Fotso, A., and Drancourt, M. (2015). Laboratory diagnosis of tickborne african relapsing fevers: latest developments. Front. Pub. Heal. 3:254. doi: 10.3389/fpubh.2015.00254

Gatton, M. L., Chitnis, N., Churcher, T., Donnelly, M. J., Ghani, A. C., Godfray, H. C., et al. (2013). The importance of mosquito behavioural adaptations to malaria control in Africa. Evolution 67, 1218-1230. doi: 10.1111/evo.12063

Gendrin, M., Rodgers, F. H., Yerbanga, R. S., Ouedraogo, J. B., Basanez, M. G., Cohuet, A., et al. (2015). Antibiotics in ingested human blood affect the 
mosquito microbiota and capacity to transmit malaria. Nat. Commun. 6, 5921. doi: $10.1038 /$ ncomms6921

Geoghegan, V., Stainton, K., Rainey, S. M., Ant, T. H., Dowle, A. A., Larson, T., et al. (2017). Perturbed cholesterol and vesicular trafficking associated with dengue blocking in Wolbachia-infected Aedes aegypti cells. Nat. Commun. 8, 526. doi: 10.1038/s41467-017-00610-8

Gething, P. W., Van Boeckel, T. P., Smith, D. L., Guerra, C. A., Patil, A. P., Snow, R. W., et al. (2011). Modelling the global constraints of temperature on transmission of Plasmodium falciparum and P. vivax. Parasit. Vectors 4:92. doi: 10.1186/1756-3305-4-92

Gimonneau, G., Pombi, M., Dabire, R. K., Diabate, A., Morand, S., and Simard, F. (2012). Behavioural responses of Anopheles gambiae sensu stricto M and S molecular form larvae to an aquatic predator in Burkina Faso. Parasit. Vectors 5:65. doi: 10.1186/1756-3305-5-65

Gimonneau, G., Tchioffo, M. T., Abate, L., Boissiere, A., Awono-Ambene, P. H., Nsango, S. E., et al. (2014). Composition of Anopheles coluzzii and Anopheles gambiae microbiota from larval to adult stages. Infect. Genet. Evol. 28, 715-724. doi: 10.1016/j.meegid.2014.09.029

Gouagna, L. C., Kerampran, R., Lebon, C., Brengues, C., Toty, C., Wilkinson, D. A., et al. (2014). Sugar-source preference, sugar intake and relative nutritional benefits in Anopheles arabiensis males. Acta Trop. 132(Suppl. 1), S70-S79. doi: 10.1016/j.actatropica.2013.09.022

Gunalan, K., Lo, E., Hostetler, J. B., Yewhalaw, D., Mu, J., Neafsey, D. E., et al. (2016). Role of Plasmodium vivax Duffy-binding protein 1 in invasion of Duffy-null Africans. Proc. Natl. Acad. Sci. U.S.A. 113, 6271-6276. doi: $10.1073 /$ pnas. 1606113113

Han, Y. S., Thompson, J., Kafatos, F. C., and Barillas-Mury, C. (2000). Molecular interactions between Anopheles stephensi midgut cells and Plasmodium berghei: the time bomb theory of ookinete invasion of mosquitoes. EMBO J. 19, 6030-6040. doi: 10.1093/emboj/19.22.6030

Harris, C., Lambrechts, L., Rousset, F., Abate, L., Nsango, S. E., Fontenille, D., et al. (2010). Polymorphisms in Anopheles gambiae immune genes associated with natural resistance to Plasmodium falciparum. PLoS Pathog. 6:e1001112. doi: 10.1371/journal.ppat.1001112

Hatle, J. D., Wells, S. M., Fuller, L. E., Allen, I. C., Gordy, L. J., Melnyk, S., et al. (2006). Calorie restriction and late-onset calorie restriction extend lifespan but do not alter protein storage in female grasshoppers. Mech. Ageing Dev. 127, 883-891. doi: 10.1016/j.mad.2006.09.003

Hemingway, J., Ranson, H., Magill, A., Kolaczinski, J., Fornadel, C., Gimnig, J., et al. (2016). Averting a malaria disaster: will insecticide resistance derail malaria control? Lancet 387, 1785-1788. doi: 10.1016/S0140-6736(15)00 417-1

Hughes, G. L., Rivero, A. A., and Rasgon, J. L. (2014). Wolbachia can enhance Plasmodium infection in mosquitoes: implications for malaria control?. PLoS Pathog. 4, 9. doi: 10.1371/journal.ppat.1004182

Hughes, G. L., Xue, P., and Rasgon, J. L. (2012). Wolbachia strain wAlbB enhances infection by the rodent malaria parasite Plasmodium berghei in Anopheles gambiae mosquitoes. Appl. Environ. Microbiol. 78, 1491-1495. doi: 10.1128/AEM.06751-11

Impoinvil, D. E., Kongere, J. O., Foster, W. A., Njiru, B. N., Killeen, G. F., Githure, J. I., et al. (2004). Feeding and survival of the malaria vector Anopheles gambiae on plants growing in Kenya. Med. Vet. Entomol. 18, 108-115. doi: 10.1111/j.0269-283X.2004.00484.X

Iqbal, M. M. (1999). Can we get AIDS from mosquito bites? J. La. State Med. Soc. $151,429-433$.

Jiggins, F. M. (2017). The spread of Wolbachia through mosquito populations. PLoS Biol. 15:e2002780. doi: 10.1371/journal.pbio.2002780

Joshi, H., Valecha, N., Verma, A., Kaul, A., Mallick, P. K., Shalini, S., et al. (2007). Genetic structure of Plasmodium falciparum field isolates in eastern and north-eastern India. Malar. J. 6:60. doi: 10.1186/1475-2875-6-60

Kabula, B., Tungu, P., Rippon, E. J., Steen, K., Kisinza, W., Magesa, S., et al. (2016). A significant association between deltamethrin resistance, Plasmodium falciparum infection and the Vgsc-1014S resistance mutation in Anopheles gambiae highlights the epidemiological importance of resistance markers. Malar. J. 15, 289. doi: 10.1186/s12936-016-1331-5

Kagira, J. M., Maina, N., Njenga, J., Karanja, S. M., Karori, S. M., and Ngotho, J. M. (2011). Prevalence and types of coinfections in sleeping sickness patients in kenya (2000/2009). J. Trop. Med. 2011:248914. doi: 10.1155/2011/248914
Kawada, H., Dida, G. O., Ohashi, K., Komagata, O., Kasai, S., Tomita, T., et al. (2011). Multimodal pyrethroid resistance in malaria vectors, Anopheles gambiae s.s., Anopheles arabiensis, and Anopheles funestus s.s. in western Kenya. PLoS ONE 6:e22574. doi: 10.1371/journal.pone.0022574

Knapp, K. L., and Rice, N. A. (2015). Human coinfection with Borrelia burgdorferi and Babesia microti in the United States. J. Parasitol. Res. 2015:587131. doi: $10.1155 / 2015 / 587131$

Kobylinski, K. C., Foy, B. D., and Richardson, J. H. (2012). Ivermectin inhibits the sporogony of Plasmodium falciparum in Anopheles gambiae. Malar. J. 11:381. doi: 10.1186/1475-2875-11-381

Kone, A., van de Vegte-Bolmer, M., Siebelink-Stoter, R., van Gemert, G. J., Dara, A., Niangaly, H., et al. (2010). Sulfadoxine-pyrimethamine impairs Plasmodium falciparum gametocyte infectivity and Anopheles mosquito survival. Int. J. Parasitol. 40, 1221-1228. doi: 10.1016/j.ijpara.2010.05.004

Labaied, M., Jayabalasingham, B., Bano, N., Cha, S. J., Sandoval, J., Guan, G., et al. (2011). Plasmodium salvages cholesterol internalized by LDL and synthesized de novo in the liver. Cell. Microbiol. 13, 569-586. doi: $10.1111 / j .1462-5822.2010 .01555 . x$

Lefevre, T., Vantaux, A., Dabire, K. R., Mouline, K., and Cohuet, A. (2013). Non-genetic determinants of mosquito competence for malaria parasites. PLoS Pathog. 9:e1003365. doi: 10.1371/journal.ppat.1003365

Lockyer, A. E., Emery, A. M., Kane, R. A., Walker, A. J., Mayer, C. D., Mitta, G., et al. (2012). Early differential gene expression in haemocytes from resistant and susceptible Biomphalaria glabrata strains in response to Schistosoma mansoni. PLoS ONE 7:e51102. doi: 10.1371/journal.pone.0051102

Lover, A. A. (2014). Note on the origin of the Madagascar strain of Plasmodium vivax. Am. J. Trop. Med. Hyg. 91, 1283. doi: 10.4269/ajtmh.14-0507

Lu, F., Culleton, R., Zhang, M., Ramaprasad, A., von Seidlein, L., Zhou, H., et al. (2017). Emergence of indigenous artemisinin-resistant Plasmodium falciparum in Africa. N. Engl. J. Med. 376, 991-993. doi: 10.1056/NEJMc1612765

Madamet, M., Kounta, M. B., Wade, K. A., Lo, G., Diawara, S., Fall, M., et al. (2017). Absence of association between polymorphisms in the K13 gene and the presence of Plasmodium falciparum parasites at day 3 after treatment with artemisinin derivatives in Senegal. Int. J. Antimicrob. Agents 49, 754-756. doi: 10.1016/j.ijantimicag.2017.01.032

McGraw, E. A., and O'Neill, S. L. (2013). Beyond insecticides: new thinking on an ancient problem. Nat. Rev. Microbiol. 11, 181-193. doi: 10.1038/nrmicro2968

Medeiros, M. C., A. T., Higashiguchi, J. M., Kitron, U. D., Walker, E. D., Brawn, J. D., Krebs, B. L., R. M., et al. (2014). An inverse association between West Nile virus serostatus and avian malaria infection status. Parasit. Vectors 7:415. doi: 10.1186/1756-3305-7-415

Mediannikov, O., Socolovschi, C., Edouard, S., Fenollar, F., Mouffok, N., Bassene, H., et al. (2013). Common epidemiology of Rickettsia felis infection and malaria, Africa. Emerg. Infect. Dis. 19, 1775-1783. doi: 10.3201/eid1911.130361

Menard, D., Barnadas, C., Bouchier, C., Henry-Halldin, C., Gray, L. R., Ratsimbasoa, A., et al. (2010). Plasmodium vivax clinical malaria is commonly observed in Duffy-negative Malagasy people. Proc. Natl. Acad. Sci. U.S.A. 107, 5967-5971. doi: 10.1073/pnas.0912496107

Mitri, C., Jacques, J. C., Thiery, I., Riehle, M. M., Xu, J., Bischoff, E., et al. (2009). Fine pathogen discrimination within the APL1 gene family protects Anopheles gambiae against human and rodent malaria species. PLoS Pathog. 5:e1000576. doi: 10.1371/journal.ppat.1000576

Molina-Cruz, A., DeJong, R. J., Ortega, C., Haile, A., Abban, E., Rodrigues, J., et al. (2012). Some strains of Plasmodium falciparum, a human malaria parasite, evade the complement-like system of Anopheles gambiae mosquitoes. Proc. Natl. Acad. Sci. U.S.A. 109, E1957-E1962. doi: 10.1073/pnas.1121183109

Moreira, L. A., Iturbe-Ormaetxe, I., Jeffery, J. A., Lu, G., Pyke, A. T., Hedges, L. M., et al. (2009). A Wolbachia symbiont in Aedes aegypti limits infection with dengue, Chikungunya, and Plasmodium. Cell 139, 1268-1278. doi: $10.1016 /$ j.cell.2009.11.042

Mourembou, G., Fenollar, F., Socolovschi, C., Lemamy, G. J., Nzoughe, H., Kouna, L. C., et al. (2015). Molecular detection of fastidious and common bacteria as well as plasmodium spp. in febrile and afebrile children in franceville, gabon. Am. J. Trop. Med. Hyg. 92, 926-932. doi: 10.4269/ajtmh.14-0699

Mousson, L., Zouache, K., Arias-Goeta, C., Raquin, V., Mavingui, P., and Failloux, A. B. (2012). The native Wolbachia symbionts limit transmission of dengue virus in Aedes albopictus. PLoS Negl. Trop. Dis. 6:e1989. doi: 10.1371/journal.pntd.0001989 
Muller, G. C., Beier, J. C., Traore, S. F., Toure, M. B., Traore, M. M., Bah, S., et al. (2010). Field experiments of Anopheles gambiae attraction to local fruits/seedpods and flowering plants in Mali to optimize strategies for malaria vector control in Africa using attractive toxic sugar bait methods. Malar. J. 9:262. doi: 10.1186/1475-2875-9-262

Murdock, C. C., Sternberg, E. D., and Thomas, M. B. (2016). Malaria transmission potential could be reduced with current and future climate change. Sci. Rep. 6:7771. doi: 10.1038/srep27771

Muturi, E. J., Jacob, B. G., Kim, C. H., Mbogo, C. M., and Novak, R. J. (2008). Are coinfections of malaria and filariasis of any epidemiological significance? Parasitol. Res. 102, 175-181. doi: 10.1007/s00436-007-0779-1

Naing, C., Whittaker, M. A., Nyunt-Wai, V., Reid, S. A., Wong, S. F., Mak, J. W., et al. (2013). Malaria and soil-transmitted intestinal helminth co-infection and its effect on anemia: a meta-analysis. Trans. R. Soc. Trop. Med. Hyg. 107, 672-683. doi: 10.1093/trstmh/trt086

Ngom, E. H. M., Ndione., J. A., Ba, Y., Konaté, L., Faye, O., Diallo, M., et al. (2013). Spatio-temporal analysis of host preferences and feeding patterns of malaria vectors in the sylvo-pastoral area of Senegal: impact of landscape classes. Parasit. Vectors 6:332. doi: 10.1186/1756-3305-6-332.

Nsango, S. E., Abate, L., Thoma, M., Pompon, J., Fraiture, M., Rademacher, A., et al. (2012). Genetic clonality of Plasmodium falciparum affects the outcome of infection in Anopheles gambiae. Int. J. Parasitol. 42, 589-595. doi: 10.1016/j.ijpara.2012.03.008

Nsango, S. E., Pompon, J., Xie, T., Rademacher, A., Fraiture, M., Thoma, M., et al. (2013). AP-1/Fos-TGase2 axis mediates wounding-induced Plasmodium falciparum killing in Anopheles gambiae. J. Biol. Chem. 288, 16145-16154. doi: 10.1074/jbc.M112.443267

Ofulla, A. V. O., Karanja, D., Omondi, R., Okurut, T., Matano, A., Jembe, T., et al. (2010). Relative abundance of mosquitoes and snails associated with hyacinth and hippo grass in the Nyanza gulf of Lake Victoria. Lakes Reservoirs 15, 255-271. doi: 10.1111/j.1440-1770.2010.00434.x

Ondeto, B. M., Nyundo, C., Kamau, L., Muriu, S. M., Mwangangi, J. M., Njagi, K., et al. (2017). Current status of insecticide resistance among malaria vectors in Kenya. Parasit. Vectors 10:429. doi: 10.1186/s13071-017-2361-8

Orlov, M., Vaida, F., Finney, O. C., Smith, D. M., Talley, A. K., Wang, R., et al. (2012). P. falciparum enhances HIV replication in an experimental malaria challenge system. PLoS ONE 7:e39000. doi: 10.1371/journal.pone.0039000

Paaijmans, K. P., Blanford, S., Bell, A. S., Blanford, J. I., Read, A. F., and Thomas, M. B. (2010). Influence of climate on malaria transmission depends on daily temperature variation. Proc. Natl. Acad. Sci. U.S.A. 107, 15135-15139. doi: $10.1073 /$ pnas.1006422107

Pinaud, S., Portela, J., Duval, D., Nowacki, F. C., Olive, M. A., Allienne, J. F., et al. (2016). A shift from cellular to humoral responses contributes to innate immune memory in the vector snail Biomphalaria glabrata. PLoS Pathog. 12:e1005361. doi: 10.1371/journal.ppat.1005361

Ranson, H., and Lissenden, N. (2016). Insecticide resistance in african anopheles mosquitoes: a worsening situation that needs urgent action to maintain malaria control. Trends Parasitol. 32, 187-196. doi: 10.1016/j.pt.2015.11.010

Riehle, M. M., M. K., Niaré, O., Xu, J., Li, J., Touré A. M., Podiougou, B., et al. (2006). Natural malaria infection in Anopheles gambiae is regulated by a single genomic control region. Science 312, 577-579. doi: 10.1126/science. 1124153

Riveron, J. M., Osae, M., Egyir-Yawson, A., Irving, H., Ibrahim, S. S., and Wondji, C. S. (2016). Multiple insecticide resistance in the major malaria vector Anopheles funestus in southern Ghana: implications for malaria control. Parasit. Vectors 9:504. doi: 10.1186/s13071-016-1787-8

Roper, C., A. M., Ariey, F., Talisuna, A., Menard, D., Mercereau-Puijalon, O., et al., (2014). Molecular surveillance for artemisinin resistance in Africa. Lancet Infect. Dis. 14, 668-670. doi: 10.1016/S1473-3099(14)70826-6.

Rossio, J. L., Esser, M. T., Suryanarayana, K., Schneider, D. K., Bess, J. W. Jr., Vasquez, G. M., et al. (1998). Inactivation of human immunodeficiency virus type 1 infectivity with preservation of conformational and functional integrity of virion surface proteins. J. Virol. 72, 7992-8001.

Rotureau, B., and Van Den Abbeele, J. (2013). Through the dark continent: African trypanosome development in the tsetse fly. Front. Cell. Infect. Microbiol. 3:53. doi: $10.3389 /$ fcimb.2013.00053

Russell, T. L. Govella, N. J., Azizi, S., Drakeley, C. J., Kachur, S. P., and Killeen, G. F. (2011). Increased proportions of outdoor feeding among residual malaria vector populations following increased use of insecticide-treated nets in rural Tanzania. Malar. J. 10:80. doi: 10.1186/1475-2875-10-80

Ryan, J. R., S. J., Amon, J., Dunton, R. F., Mtalib, R., Koros, J., Owour, B., et al. (2006). Evidence for transmission of Plasmodium vivax among a duffy antigen negative population in Western Kenya. Am. J. Trop. Med. Hyg. 75, 575-581. doi: 10.4269/ajtmh.2006.75.575

Saraiva, R. G., Kang, S., Simoes, M. L., Anglero-Rodriguez, Y. I., and Dimopoulos, G. (2016). Mosquito gut antiparasitic and antiviral immunity. Dev. Comp. Immunol. 64, 53-64. doi: 10.1016/j.dci.2016.01.015

Scott, T. W., and Takken, W. (2012). Feeding strategies of anthropophilic mosquitoes result in increased risk of pathogen transmission. Trends Parasitol. 28, 114-121. doi: 10.1016/j.pt.2012.01.001

Shapiro, L. L. M., Whitehead, S. A., and Thomas, M. B. (2017). Quantifying the effects of temperature on mosquito and parasite traits that determine the transmission potential of human malaria. PLoS Biol. 15:e2003489. doi: 10.1371/journal.pbio.2003489

Silbermayr, K., L. F., Soudré, A., Müller, S., and Sölkner, J. (2013). A novel qPCR assay for the detection of African animal trypanosomosis in trypanotolerant and trypanosusceptible cattle breeds. PLoS Negl. Trop. Dis. 7:e2345. doi: 10.1371/journal.pntd.0002345

Silva, A. P., Santos, J. M., and Martins, A. J. (2014). Mutations in the voltage-gated sodium channel gene of anophelines and their association with resistance to pyrethroids - a review. Parasit. Vectors 7:450. doi: 10.1186/1756-3305-7-450

Smith, R. C., Vega-Rodríguez, J., and Jacobs-Lorena, M. (2014). The Plasmodium bottleneck: malaria parasite losses in the mosquito vector. Memórias do Instituto Oswaldo Cruz 109, 644-661. doi: 10.1590/0074-0276130597

Smith, T., Felger, I., Kitua, A., Tanner, M., and Beck, H. P. (1999). Dynamics of multiple Plasmodium falciparum infections in infants in a highly endemic area of Tanzania. Trans. R. Soc. Trop. Med. Hyg. 93 (Suppl. 1), 35-39.

Sokhna, C., Le Hesran, J. Y., Mbaye, P. A., Akiana, J., Camara, P., Diop, M., et al. (2004). Increase of malaria attacks among children presenting concomitant infection by Schistosoma mansoni in Senegal. Malar. J. 3:43. doi: 10.1186/1475-2875-3-43

Sothmann, P., Keller, C., Krumkamp, R., Kreuels, B., Aldrich, C., Sarpong, N., et al. (2017). Rickettsia felis infection in febrile children, Ghana. Am. J. Trop. Med. Hyg. 96, 783-785. doi: 10.4269/ajtmh.16-0754

Sow, A., Loucoubar, C., Diallo, D., Faye, O., Ndiaye, Y., Senghor, C. S., et al. (2016). Concurrent malaria and arbovirus infections in Kedougou, southeastern Senegal. Malar. J. 15, 47. doi: 10.1186/s12936-016-1100-5.

Takken, W., and Verhulst, N. O. (2013). Host preferences of blood-feeding mosquitoes. Annu. Rev. Entomol. 58, 433-453. doi: 10.1146/annurev-ento-120811-153618

Tchioffo, M. T., Boissiere, A., Abate, L., Nsango, S. E., Bayibeki, A. N., Awono-Ambene, P. H., et al. (2015). Dynamics of bacterial community composition in the malaria mosquito's Epithelia. Front. Microbiol. 6:1500. doi: 10.3389/fmicb.2015.01500

Tchioffo, M. T., Boissiere, A., Churcher, T. S., Abate, L., Gimonneau, G., Nsango, S. E., et al. (2013). Modulation of malaria infection in Anopheles gambiae mosquitoes exposed to natural midgut bacteria. PLoS ONE 8:e81663. doi: 10.1371/journal.pone.0081663

Trape, J. F., Rogier, C., Konate, L., Diagne, N., Bouganali, H., Canque, B., et al. (1994). The Dielmo project: a longitudinal study of natural malaria infection and the mechanisms of protective immunity in a community living in a holoendemic area of Senegal. Am. J. Trop. Med. Hyg. 51, 123-137.

Tun, K. M., Imwong, M., Lwin, K. M., Win, A. A., Hlaing, T. M., Hlaing, T., et al. (2015). Spread of artemisinin-resistant Plasmodium falciparum in Myanmar: a cross-sectional survey of the K13 molecular marker. Lancet Infect. Dis. 15, 415-421. doi: 10.1016/S1473-3099(15)70032-0

Vellai, T., Takacs-Vellai, K., Zhang, Y., Kovacs, A. L., Orosz, L., and Muller, F. (2003). Genetics: influence of TOR kinase on lifespan in C. elegans. Nature 426, 620. doi: $10.1038 / 426620$ a

Vernick, K. D., W. A. (2004). Genomics and malaria control. N. Engl. J. Med. 351, 1901-1904. doi: 10.1056/NEJMcibr042899

Walker, T., Johnson, P. H., Moreira, L. A., Iturbe-Ormaetxe, I., Frentiu, F. D., McMeniman, C. J., et al. (2011). The wMel Wolbachia strain blocks dengue and invades caged Aedes aegypti populations. Nature 476, 450-453. doi: 10.1038/ nature 10355

Weiss, R. A. (1993). How does HIV cause AIDS? Science 260, 1273-1279. 
Wilson, S., and Dunne, D. W. (2012). Advances in our understanding of the epidemiology of Plasmodium and schistosome infection: informing coinfection studies. Curr. Opin. HIV AIDS 7, 225-230. doi: 10.1097/COH.0b013e328351b9fb

Woldearegai, T. G., K. P., Kun, J. F., and Mordmüller, B. (2013). Plasmodium vivax malaria in Duffy-negative individuals from Ethiopia. Trans. R. Soc. Trop. Med. Hyg. 107, 328-331. doi: 10.1093/trstmh/trt016

Zélé, F., Nicot, A., Berthomieu, A., Weill, M., Duron, O., and Rivero, A. (2014a). Wolbachia increases susceptibility to Plasmodium infection in a natural system. Proc. Biol. Sci. 281:20132837. doi: 10.1098/rspb.2013.2837

Zélé, F., Vézilier, J., L'Ambert, G., Nicot, A., Gandon, S., Rivero, A., et al. (2014b). Dynamics of prevalence and diversity of avian malaria infections in wild Culex pipiens mosquitoes: the effects of Wolbachia, filarial nematodes and insecticide resistance. Parasit. Vectors. 7:437. doi: 10.1186/1756-3305$7-437$
Zielke, E., Schulz-Key, H., and Albiez, E. J. (1977). On the development of Onchocerca volvulus in mosquitoes. Tropenmed. Parasitol. 28, 254-257.

Conflict of Interest Statement: The authors declare that the research was conducted in the absence of any commercial or financial relationships that could be construed as a potential conflict of interest.

The reviewer AM and handling Editor declared their shared affiliation.

Copyright (C) 2017 Dieme, Rotureau and Mitri. This is an open-access article distributed under the terms of the Creative Commons Attribution License (CC BY).

The use, distribution or reproduction in other forums is permitted, provided the original author(s) or licensor are credited and that the original publication in this journal is cited, in accordance with accepted academic practice. No use, distribution or reproduction is permitted which does not comply with these terms. 